|| ISSN(online): 2589-8698 || ISSN(print): 2589-868X ||

International Journal of Medical and Biomedical Studies

Available Online at www.ijmbs.info

NLM (National Library of Medicine ID: 101738825)

Index Copernicus Value 2019: 79.34

Original Research Article

Volume 5, Issue 7; July: 2021; Page No. 24-27

\title{
FETOMATERNAL OUTCOME IN PREGNANCY WITH CARDIAC DISEASE
}

\section{Dr. Kalyani K Bafna ${ }^{1}$, Dr. Kanaklata Nakum $^{2}$, Dr. Aditi Vithal ${ }^{3}$}

${ }^{1} 3^{\text {rd }}$ Year Resident in Department of Obs and Gynec., Government Medical College, Bhavnagar.

${ }^{2}$ Associate Prof. \& in charge HOD in Department of Obs. and Gynec., Government Medical College, Bhavnagar.

${ }^{3}$ Assistant Professor, in Department of Obs. and Gynec., Government Medical College, Bhavnagar.

Article Info: Received 05 May 2021; Accepted 29 June 2021

DOI: https://doi.org/10.32553/ijmbs.v5i7.2007

Corresponding author: Dr. Kanaklata Nakum

Conflict of interest: No conflict of interest.

\section{Abstract}

Objective(S): Cardiac disease is an important cause of maternal morbidity and mortality in both antepartum as well as in postpartum period. Incidence of heart disease with pregnancy is $<1 \%$. Aim of this study is to determine maternal complications with heart disease, mode of delivery \& fetal complications.

Materials \& Methodology: This is a retrospective study conducted at Gopinath Maternity Home, Sir-T Hospital, Bhavnagar. From May 2020- April 2021. All pregnant women with various cardiac disease (previously established or diagnosed during pregnancy) who came to labor room or OPD are included.

Result: 30 pregnant women out of 2683 deliveries were identified with cardiac disease giving prevalence of $1.12 \%$ in this study. $15(50 \%)$ women belonging to NYHA class-1 \& 8(26.6\%) belonged to NYHA class 2 . Class $3(3$ patients $=10 \%) \&$ class $4(4$ patients $=13.3 \%)$ were admitted immediately. $18(60 \%)$ women were case of valvular heart disease, out of which 12(66.6\%) cases were of RHD, 2(11.1\%) were MS, 3(16.6\%) AS, 1(5.5\%) MR. 10(33.33\%) cases were congenital heart disease. Maternal mortality were $4(13.33 \%)$. Out of 30 cases, $18(69.2 \%)$ women had LSCS, 6(23.07\%) had vaginal delivery,2(7.7\%) had vaccum \& 3(10.3\%) had abortion. Out of 26 deliveries 2(7.7\%) were IUFD, 6(23.07\%) Preterm, 7(26.9\%) IUGR. Total there were $9(37.5 \%)$ NICU admissions.

Conclusion: Prognosis of pregnancy with heart disease has improved but management of it is still a challenge for obstetricians. Pre-conceptional counseling plays an important role by benefiting women with severe heart disease and thus help in reducing maternal morbidity and mortality.

Keywords: cardiac disease, maternal outcome, fetal outcome

\section{Introduction}

- Heart disease in pregnancy is a high risk condition with increased risk of maternal and fetal morbidity and mortality.

- It is an important cause of maternal morbidity and mortality both in antepartum as well as postpartum period.

- It is mainly divided into congenital heart disease and acquired heart disease.

- It occurs in $<1 \%$ pregnancies.

- Most common heart disease in pregnancy in developing countries is Acquired Heart Disease (Mitral Stenosis).

It occurs in $<1 \%$ pregnancies.

Most common heart disease in pregnancy in developing countries is Acquired Heart Disease (Mitral Stenosis).

Most common heart disease in pregnancy in developed countries is Congenital Heart Disease (ASD).

Heart disease with highest maternal mortality is Eisenmenger Syndrome.

Maternal mortality is most commonly seen with MS.

NYHA CLASSIFICATION OF HEART DISEASE

Grade 1: Uncompromised or no limitation of physical activity.
Grade 2: Slightly compromised with discomfort on ordinary physical work.

Grade 3: Markedly compromised with discomfort on doing less than ordinary work

Grade 4: Severely compromised with discomfort even at rest.

CLARKE'S CLASSIFICATION OF HEART DISEASE

Class 1: Cardiac Disease with minimal risk (mortality 0$1 \%$ )

Class 2: Moderate Risk (5-15\%)

Class 3: Major Risk (25-50\%)

NORMAL PHYSIOLOGICAL CHANGES IN CVS IN PREGNANCY

PARAMETERS WHICH INCREASE:

1. Cardiac Output $\uparrow:$ Immediate postpartum $>2$ nd stage of labour > late 1st stage of labour $>28-32$ weeks of pregnancy

2. Pulse rate

3. Stroke volume

4. Femoral venous pressure

5. Preload

PARAMETERS WHICH DECREASE: 
1. BP

2. Afterload

3. Arterial venous oxygen gradient.

NORMAL CHANGES

1. Loud S1 with wide split

2. $\mathrm{S} 3$ is heard

3. Ejection systolic murmur of grade 1 and 2

4. Soft transient diastolic murmur

5. Mild cardiomegaly

6. Left axis deviation

7. Straightening of left heart border.

\section{AIMS AND OBJECTIVES}

To determine feto-maternal outcome and to evaluate prognosis in such pregnancies.

To determine prevalence of cardiac disease in pregnant women.

To discuss antepartum and intrapartum management.

To suggest suitable contraception and counsel the need for strict adherence.

\section{Methodology}

Study Design: Retrospective study.

Study Population \& Duration: May 2020 - April 2021, carried out in pregnant women with cardiac disease in department of Obstetric \& Gynecology at Sir T Hospital, Bhavnagar.

Total number of deliveries 2683.

Sample size: Study was carried out on 30 cases with various cardiac diseases during pregnancy by analyzing their case sheets.

Inclusion criteria: All pregnant women with newly diagnosed or with previous history of heart diseases.

Basic details like age, gestational age, clinical features, associated heart disease, mode of delivery and fetal outcome were noted from case records.

All these information was gathered and results were analyzed and results were obtained accordingly.

\section{Results}

Table 1: Pregnant women with various cardiac disease

\begin{tabular}{|l|l|}
\hline HEART DISEASE & TOTAL CASES (30) \\
\hline CONGENITAL HEART DISEASE & $10(33.33 \%)$ \\
\hline CYANOTIC HEART DISEASE & $04(13.33 \%)$ \\
\hline VALVULAR HEART DISEASE & $20(66.66 \%)$ \\
\hline RHEUMATIC HEART DISEASE & $14(46.66 \%)$ \\
\hline PULLMONARY ARTERY HYPERTENSION & $02(06.66 \%)$ \\
\hline
\end{tabular}

Table 2: Mode of delivery

\begin{tabular}{|l|l|l|l|l|l|}
\hline \multicolumn{2}{|l|}{ LSCS $18(69.2 \%)$} & \multicolumn{2}{l|}{ VAGINAL DELIVERY 06 (23.07\%) } & \multicolumn{2}{l|}{ VENTOSE 02 (07.77\%) } \\
\hline TERM & PRETERM & TERM & PRETERM & TERM & PRETERM \\
\hline $14(48.27 \%)$ & $04(13.79 \%)$ & $05(17.24 \%)$ & $01(03.43 \%)$ & $01(03.43 \%)$ & $01(03.43 \%)$ \\
\hline
\end{tabular}

Total number of deliveries: 26

Total number of abortions: 03

Antenatal mother: 01

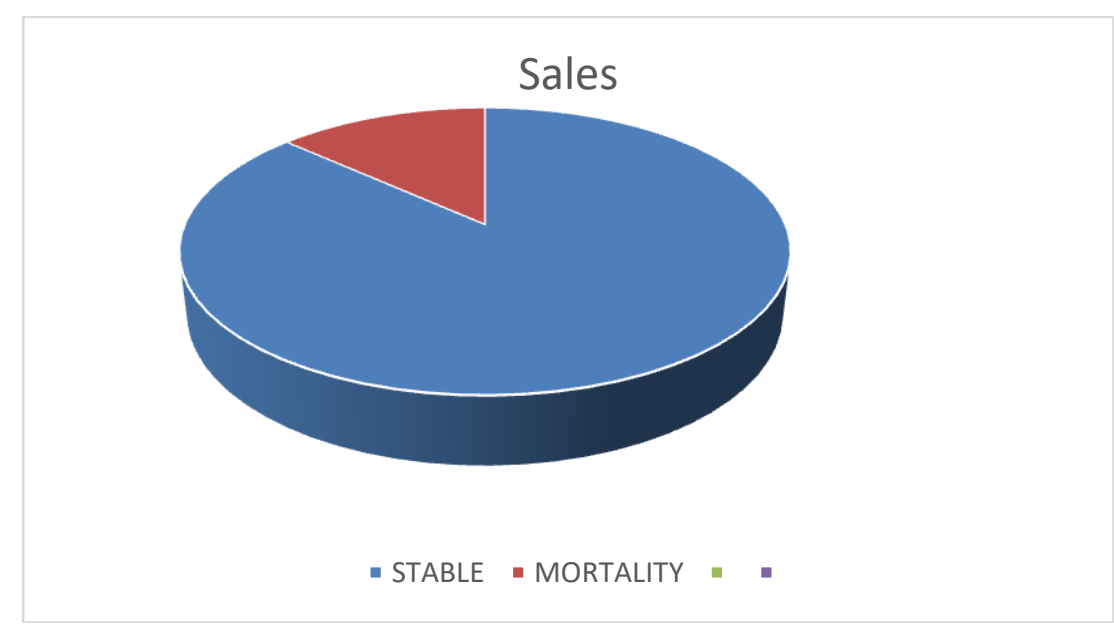

\section{Chart - 1: Maternal outcome}

Out of 30 patients, mortality occurred in 4(13.33\%) patients. 1 in antenatal period and 3 in postpartum due to CCF. 


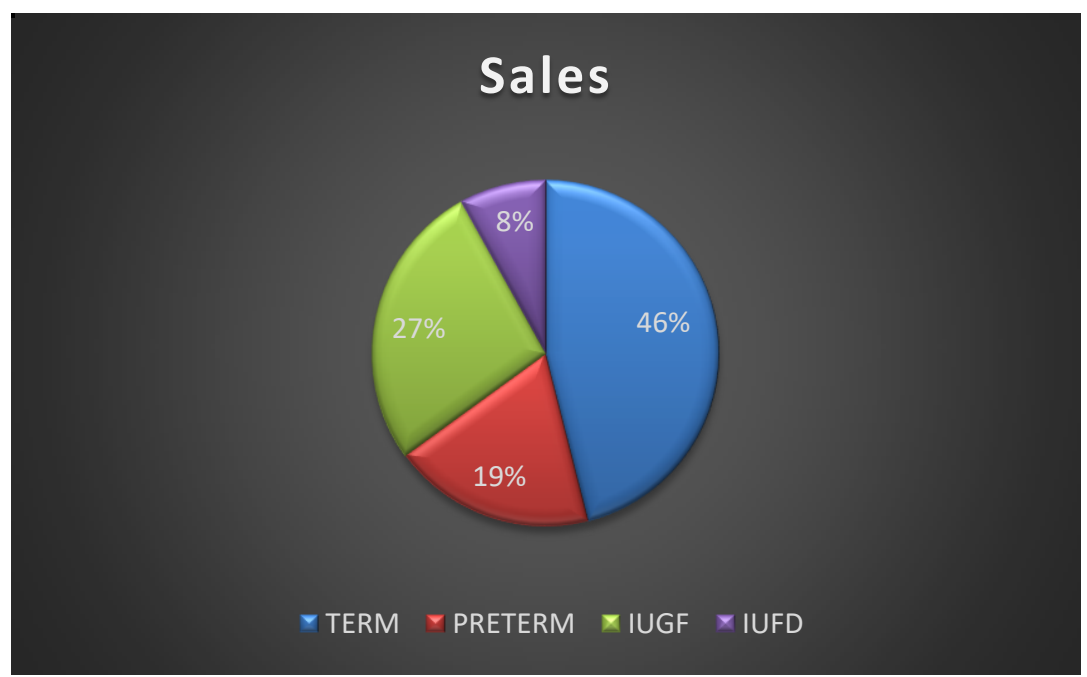

\section{Chart 2: Fetal outcome}

Out of 20 term pregnancy, 7 were IUGR, 1 was IUFD.

Out of 6 preterm deliveries, 5 were live and 1 was IUFD.

NICU admission were 9, from which 5 were preterm and 4 were IUGR.

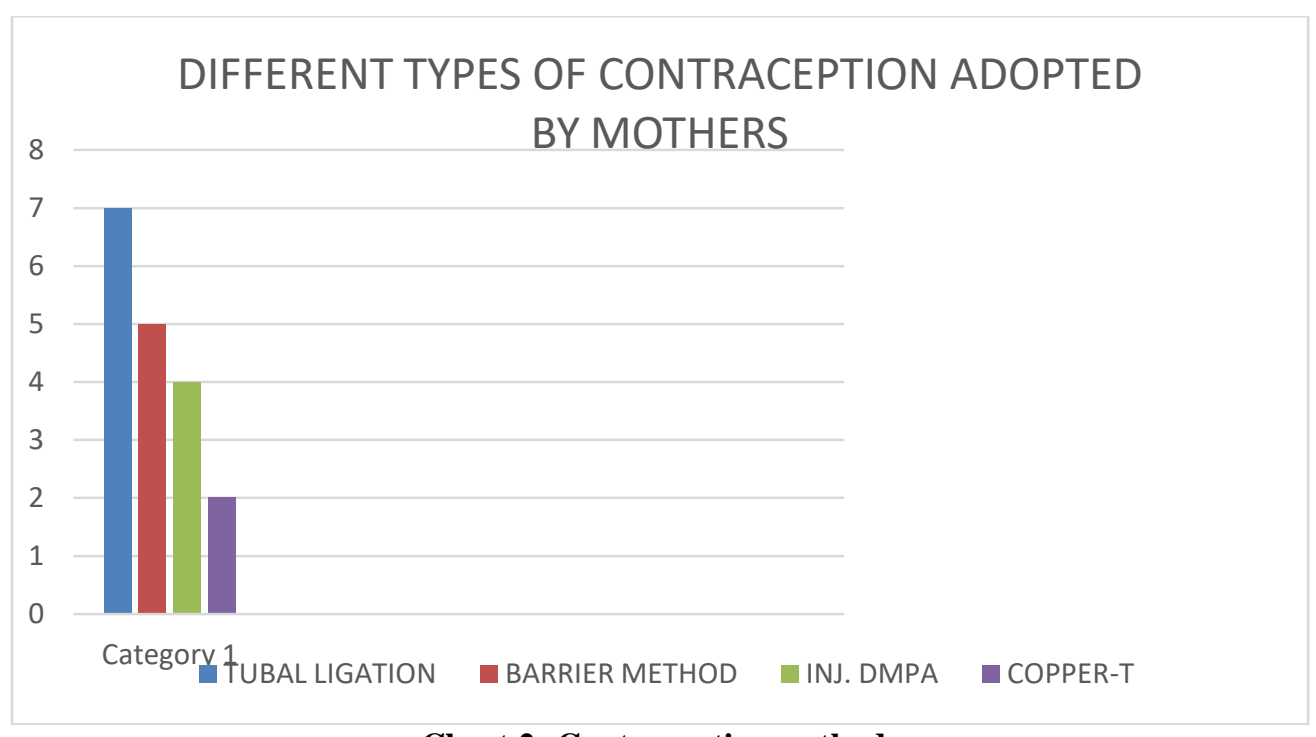

Chart 2: Contraceptive methods

7 had Tubal Ligation, 5 choose Barrier Method, 4 choose Inj. DMPA and 2 copper-T.

8 women did not choose any method of contraception indicating that more awareness should be created among them and they were advised for husband sterilization.

\section{Discussion}

30 pregnant women out of 2683 deliveries were identified with various cardiac disease giving prevalence of $1.12 \%$ in this study.

$12(40 \%)$ patients belonged to age of $20-25$ years \& $18(60 \%)$ belonged to age of 26-35years.
$15(50 \%)$ women belonging to NYHA class- $1 \& 8(26.6 \%)$ belonged to NYHA class 2 \& they all delivered uneventfully.

Class $3(3$ patients $=10 \%) \&$ class $4(4$ patients $=13.3 \%)$ were admitted immediately.

$6(20 \%)$ women had preeclampsia and $4(13.3 \%)$ had anemia as associated conditions with cardiac disease.

$18(60 \%)$ women were case of valvular heart disease, out of which 12(66.6\%) cases were of RHD, 2(11.1\%) were MS, $3(16.6 \%) \mathrm{AS}, 1(5.5 \%) \mathrm{MR}$.

$10(33.33 \%)$ cases were congenital heart disease, out of which $4(13.33 \%)$ belonged to cyanotic heart disease, 2 had ASD, 2 had VSD \& 2 had PDA. 
2 had Infective Endocarditis.

3 women developed pulmonary edema and 4 developed congestive cardiac failure.

Maternal mortality were 4(13.33\%), 1 in antepartum period, 3 in postpartum due to CCF.

Out of 30 cases, $18(69.2 \%)$ women had LSCS, 6(23.07\%) had vaginal delivery,2(7.7\%) had vaccum \& $3(10.3 \%)$ had abortion. CS with cardiac indication were 3 .

Out of 20(76,92\%) full term delivery, 14 had LSCS, 5 vaginal delivery \& 1 vaccum.

Out of $6(23.07 \%)$ preterm deliveries, 4 had LSCS, 1 Vaginal \& 1 vaccum.

Out of 26 deliveries 2(7.7\%) were IUFD, 6(23.07\%) Preterm, 7(26.9\%) IUGR. Total there were 9(37.5\%) NICU admissions (4 IUGR+5 Preterm).

7 had tubal ligation, 5 choose barrier method, 4 choose Inj. DMPA, 2 copper T.

8 women did not choose any method of contraception indicating that more awareness should be created among the people.

\section{Conclusion}

Prognosis of pregnancy with heart disease has improved but management of it is still a challenge for obstetricians.

Preconceptional counseling plays an important role by benefiting women with severe heart disease and thus help in reducing maternal morbidity and mortality.
Use of contraceptive methods to prevent unwanted pregnancy is also important.

\section{References}

1. Dawson, Angela $\mathrm{J}$ et al. "Experiences of women with cardiac disease in pregnancy: a systematic review and metasynthesis." BMJ open vol. 8,9 e022755. 28 Sep. 2018, doi:10.1136/bmjopen-2018022755 .

2. Farhan, H.A., Yaseen, I.F. Heart disease in pregnancy-clinical pattern and prevalence: initial data from the first cardio-maternal unit in Iraq. BMC Res Notes 12, 491 (2019). https://doi.org/10.1186/ s13104-019-4523-6

3. Lawlor DA, Emberson JR, Ebrahim S, Whincup PH, Wannamethee SG, Walker M, Smith GD; British Women's Heart and Health Study; British Regional Heart Study. Is the association between parity and coronary heart disease due to biological effects of pregnancy or adverse lifestyle risk factors associated with child-rearing? Findings from the British Women's Heart and Health Study and the British Regional Heart Study. Circulation. 2003 Mar 11;107(9):1260-4. doi: 10.1161/01.cir.0000053441. 43495.1a. PMID: 12628945.

4. SALAM, Samia et al. Maternal and fetal outcome in pregnancy with heart disease in tertiary care hospital in India. International Journal of Reproduction, Contraception, Obstetrics and Gynecology, [S.1.], v. 6, n. 9, p. 3947-3951, aug. 2017. ISSN 2320-1789. 